\title{
Word skipping in reading: On the interplay of linguistic and visual factors
}

\author{
Denis Drieghe \\ Ghent University, Belgium \\ Marc Brysbaert \\ Royal Holloway, University of London, UK \\ Timothy Desmet and Constantijn De Baecke \\ Ghent University, Belgium
}

\begin{abstract}
An eye movement experiment is reported in which target words of two and four letters were presented in sentences that strongly raised the expectation of a particular word. There were three possible conditions: The expected word was present in the sentence, an unexpected word of the same length was present, or an unexpected word of a different length was present (all continuations were acceptable, but the latter two were difficult to predict). Our first purpose was to test one of the core assumptions of the Extended Optimal Viewing Position model of eye guidance in reading (Brysbaert \& Vitu, 1998). This model states that word skipping is primarily a function of the length of the upcoming word. It leads to the prediction that an unpredicted two-letter word will be skipped more often than a predicted four-letter word, which is indeed what we observed. Our second aim was to determine if we could obtain an interaction between context predictability and parafoveal word length, by looking at what happens when the length of the parafoveal word does not agree with the length of the expected word. No such interaction was observed although the effects of both word length and predictability were substantial. These findings are interpreted as evidence for the hypothesis that visual and language-related factors independently affect word skipping.
\end{abstract}

Correspondence should be addressed to D. Drieghe, Dept. of Experimental Psychology, Ghent University, Henri Dunantlaan 2, B-9000 Ghent, Belgium. Email: denis.drieghe@Ugent.be

Denis Drieghe and Timothy Desmet are research assistants of the Fund for Scientific Research (Flanders, Belgium).

Due to a software error which resulted in an incorrect calculation of the skipping data, this research has previously been presented with slightly different data (Drieghe \& Brysbaert, 2001).

We thank Keith Rayner, Françoise Vitu, Sarah White, and an anonymous reviewer for the many helpful comments on earlier drafts of this paper.

(C) 2004 Psychology Press Ltd

http://www.tandf.co.uk/journals/pp/09541446.html

DOI:10.1080/09541440340000141 
One of the current controversies in research on eye movements in reading concerns the kind of information extracted from parafoveal vision and the ways in which this information influences subsequent eye movements (Starr \& Rayner, 2001). A large body of research indicates that in reading information is extracted from the word next to the currently fixated word. This parafoveal preview benefit is easily shown by comparing conditions in which the parafoveal word is visible with conditions in which it is masked until the reader's eyes land on it (e.g., Blanchard, Pollatsek, \& Rayner, 1989; Morris, Rayner, \& Pollatsek, 1990; Rayner, 1975; Rayner, Well, Pollatsek, \& Bertera, 1982; Schroyens, Vitu, Brysbaert, \& d'Ydewalle, 1999). A major issue, however, is the extent to which the parafoveal information determines the length of the subsequent forward saccade out of the fixated word. In the present paper, we will deal with the probability of fixating the next parafoveal word only, although a very similar discussion exists about the landing position within the parafoveal word.

There are two main types of factors that can influence the length of a forward saccade: low-level, visuomotor variables and high-level, language-related variables. Visuomotor factors refer to the visual characteristics of the text and to limitations in the planning and execution of eye movements. The most prominent visual characteristics related to a text are the length of the foveal and the parafoveal word and the distance of the eyes from the parafoveal word (the socalled launch site). It is well-established that word skipping occurs more frequently with short words than with long words (Brysbaert \& Vitu, 1998; Rayner, 1979; Rayner \& McConkie, 1976; Vitu, O’Regan, Inhoff, \& Topolski, 1995), and that it occurs more often when the previous fixation was close to the parafoveal word than when it was far away (Kerr, 1992; Rayner, Sereno, \& Raney, 1996; Vitu et al., 1995). The oculomotor limitations refer to the fact that in general there is some error between the intended landing position and the actual landing position. This error has a systematic component (such as the tendency to undershoot far targets) and a random component (making the landing distribution over many trials look like a normal distribution). Data from McConkie, Kerr, Reddix, and Zola (1988; see also McConkie, Kerr, \& Dyre, 1994) nicely illustrate the importance of visuomotor factors in word skipping. McConkie et al. asked participants to read a long text, in order that they could analyse a large corpus of data. When the landing sites were plotted as a function of the launch site, there were systematic differences in the mean and the standard deviation of the Gaussian landing site distributions. Each time the saccade originated from a launch site one character position further away from the beginning of the target word, the mean of the landing position distribution was shifted leftward by about one third of a character and the variance of the distribution increased. To explain the shift of the landing distribution as a function of the launch site, McConkie et al. suggested the existence of a range effect. The oculomotor systems tends to undershoot targets at a large eccentricity and to 
overshoot targets at a small eccentricity. Another oculomotor limitation that has been proposed is the so-called global effect (Gautier, O'Regan, \& Le Gargasson, 2000; Vitu, 1991). When the eyes make a saccade to a target word, the movement is influenced not only by the visual characteristics of the target word but also by the surrounding stimulus materials. This influence causes the eyes to be deviated away from the target, towards a cortically weighted centre of gravity defined by the global visual configuration surrounding the target. Applied to skipping this means that sometimes a parafoveal word will be skipped erroneously because the centre of gravity lies behind the word, or that it will be impossible to skip the word because the centre of gravity coincides with the word. Findings such as these indicate that any comprehensive theory of word skipping has to take into account involuntary word skipping or word fixation because of oculomotor error. Visuomotor factors also explain why word skipping is observed in studies where it is impossible to use language information from the parafoveal word because this word is masked until the eyes cross an invisible boundary at the beginning of the word (e.g., Blanchard et al., 1989; Rayner et al., 1982).

In addition to the low-level visuomotor factors, linguistic variables are also known to influence the probability of word skipping. A distinction can be made between characteristics at the word level (such as word frequency and visibility of the parafoveal word) and characteristics at the sentence or discourse level (such as word predictability from the context). The strongest language-related influence is the effect of contextual constraints: Words that are highly predictable from the preceding context are skipped more often than words that are not constrained (Altaribba, Kroll, Sholl, \& Rayner, 1996; Balota, Pollatsek, \& Rayner, 1985; Ehrlich \& Rayner, 1981; Rayner, Binder, Ashby, \& Pollatsek, 2001; Rayner \& Well, 1996; Schustack, Ehrlich, \& Rayner, 1987). Contextual constraint is typically assessed with a sentence completion task in which subjects are given a sentence fragment up to the target word and are asked to write down the first word that comes to mind. Words that are produced by many participants are considered to be highly constrained. Effects of word-related variables on skipping have also been observed: High-frequency words are more likely to be skipped than low-frequency words, especially when the eyes are close to the target word on the fixation prior to the skipping (Henderson \& Ferreira, 1993; Radach \& Kempe, 1993; Rayner \& Fischer, 1996; Rayner et al., 1996).

Brysbaert and Vitu (1998) were among the first to look at the effects of both types of variables together. A reason why visuomotor and linguistic variables had rarely been examined simultaneously until then is that both types of variables are highly correlated, making them difficult to disentangle. In general, high-frequency, familiar (i.e., easy) words tend to be shorter than low-frequency, unfamiliar words. To determine the relative importance of word length and word processing difficulty on word skipping probability, Brysbaert and Vitu ran a meta-analysis of all the studies that had manipulated 
the processing load of target words (by changing the word frequency or the word visibility in the parafovea) and that included information about the length of the target words. Averaged over all the studies (and the different conditions within the studies), Brysbaert and Vitu found a consistent $4 \%$ difference in skipping rate between the easy and the difficult words, confirming the claim that language-related factors have an influence on the probability of word skipping. However, at the same time they observed a strong effect of word length. Skipping rate ranged from over 50\% for two-letter target words to some $1 \%$ for nine-letter words, and this effect could be captured quite well with an exponential function. In a second analysis, they repeated the exercise for those studies that had manipulated the context predictability of the target words and had reported information about the length of the words. The effect of context predictability on skipping rate was slightly larger than that of the word-related variables and amounted to a 9\% difference between predicted and unpredicted words. The impact of word length was exactly the same as in the word-level studies. Because of the importance of these findings for the rest of the present paper, they are illustrated in Figure 1 (taken from Brysbaert \& Vitu, 1998).

On the basis of these findings, Brysbaert and Vitu (1998) concluded that it was more informative to know the length of the parafoveal word in order to predict word skipping probability than to know the ease of processing; in other words, short words are skipped mainly because they are short and not because they are easy to process. To explain how word skipping could be based on the length of the parafoveal word, Brysbaert and Vitu turned to a finding they had

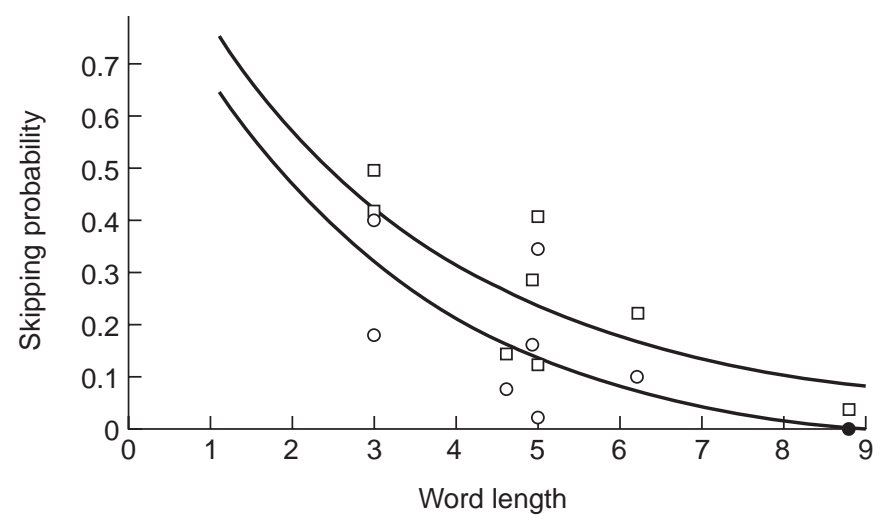

Figure 1. Skipping rate as a function of word length and contextual constraint (circle $=$ predictable conditions; square = neutral conditions). Fitted curve based on nonlinear regression with exp(word length) and contextual constraint as predictors. The upper curve represents the best fit for the predictable words; the lower curve is the best fit for the neutral words (reprinted from Brysbaert \& Vitu, 1998). 


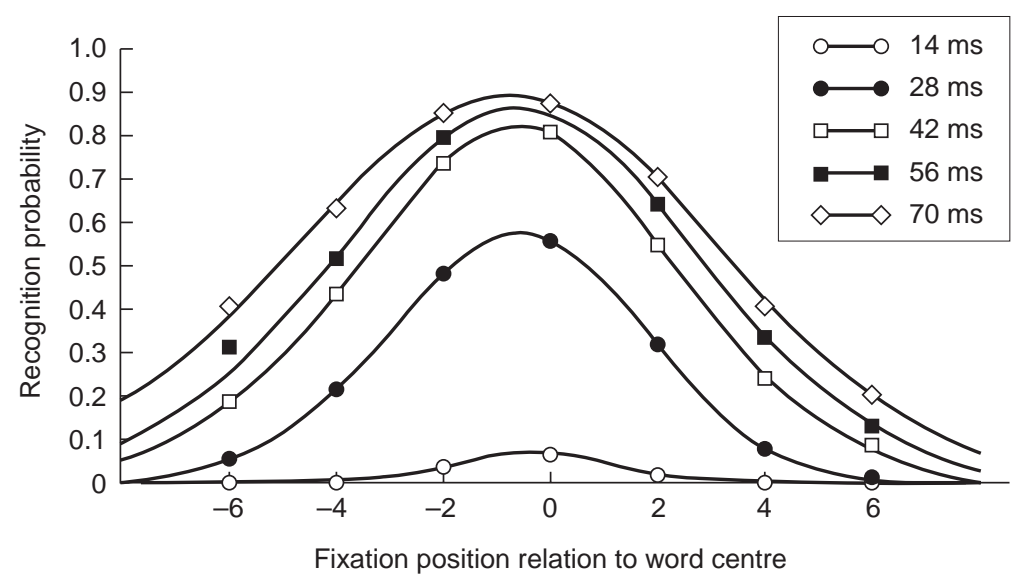

Figure 2. Probability of word recognition as a function of presentation duration and word position relative to fixation location. Empirical data and best fitting Gaussian distributions (reprinted from Brysbaert et al., 1996).

reported before (Brysbaert, Vitu, \& Schroyens, 1996). In this study, Brysbaert et al. had found that the probability of word recognition given a certain presentation duration and distance between the target word and the fixation location, could reasonably well be described by a Gaussian distribution that had the mode shifted slightly to the left of the word centre. Figure 2 depicts their finding. Brysbaert et al. called this effect, by analogy to the previously defined optimal viewing position (e.g., O’Regan \& Jacobs, 1992; O’Regan, LévySchoen, Pynte, \& Brugaillère, 1984), the Extended Optimal Viewing Position (EOVP) effect.

Brysbaert and Vitu (1998) hypothesised that the EOVP information could be used by the eye guidance system to estimate the chances of identifying the upcoming parafoveal words within the time period of an average fixation (200$220 \mathrm{~ms}$ ), and to select the most appropriate parafoveal target word. The estimates are based upon (1) the length of the word blobs ${ }^{1}$ and the distance of the word blobs from the fixation location, and (2) the standard deviation of the Gaussian EOVP curve. The latter depends on text difficulty and task demands, so that the spread of the Gaussian curve will be larger for easy texts and for cursory reading. The decision to skip a word is viewed here as an educated guess based on coarse visual information which becomes available rather early in the fixation.

Linguistic influences on skipping behaviour were included in the EOVP model as follows. Although the system disposes of an identification probability for the parafoveal word on the basis of word length and the eccentricity of the

\footnotetext{
${ }^{1}$ Brysbaert and Vitu (1998) use this term for the parafoveal word to stress the limited visibility of the words in parafoveal vision.
} 
word, it still has to "decide"' which word to pick as the most suitable parafoveal target word. This decision is taken by a system related to the discourse processing on the basis of partial information (i.e., before the word is fully recognised), or as Brysbaert and Vitu (1998, p. 142) phrased it:

According to [other] theories, a word is skipped because it was recognized during the previous fixation. According to our view, a word is skipped because the language system estimates chances high enough that it (i.e. the parafoveal word) will be identified by the end of the current fixation or, at least, that bypassing the word will not hinder text understanding.

Brysbaert and Vitu (1998) further assumed that occasionally the initial decision could be overruled by the processing rate of the parafoveal word. There are two ways in which this can happen. First, when the processing of the parafoveal word is easier than anticipated, a planned saccade to this word can be cancelled and replaced by a saccade to the next word. Alternatively, when processing of the parafoveal word turns out to be more difficult than anticipated, a planned skip can be cancelled (or shortened) so that the parafoveal word is fixated after all. Brysbaert and Vitu ventured that the latter situation could be more frequent, as it may be easier to shorten the saccade of a planned skip than to lengthen the saccade of a planned fixation. New data on saccade generation during reading (Yang \& McConkie, 2001) corroborate this idea that language processing influences eye movements not by directing each and every saccade but by interfering with an ongoing, more basic oculomotor process. Following Findlay and Walker (1999), Yang and McConkie hypothesised that saccades are initiated by a rhythmical sequence, on which cognitive interventions now and then exercise an inhibitory control. Although Yang and McConkie's Competition/Interaction theory focused on fixation durations, they also claimed that processing-related inhibition not only affects the onset time of the next saccade but also its length.

Because interword eye movements are guided primarily on the basis of word length, the EOVP model of word skipping is closer to the oculomotor family of theories than to the cognitive-processing family of theories. So, how does the latter group deal with the issue of word skipping? We will only discuss the E-Z Reader model (Rayner, Reichle, \& Pollatsek, 1998; Reichle, Pollatsek, Fisher, \& Rayner, 1998; Reichle, Rayner, \& Pollatsek, 1999, in press), which at present is the most elaborated and detailed model. According to the E-Z Reader model, word recognition in reading is a serial process under the control of an attentional beam (i.e., only the word in the attention beam is processed). The eyes follow the shift of the attentional beam with a certain delay due to the eye movement programming time. ${ }^{2}$ In E-Z Reader, word skipping is based on the following

\footnotetext{
${ }^{2}$ This idea was originally formulated by Morrison (1984) and also features in the ideas of Henderson and Ferreira (1990).
} 
sequence of events. The programming of an eye movement starts as soon as the word processing system reaches a stage from which word identification becomes likely. Reichle and colleagues called this the familiarity check. At this stage, a word is not yet fully recognised, but the dynamics in the lexicon are such that it is likely to become so within a limited time period. When the familiarity check for the currently fixated word $n$ has occurred, the eye guidance system starts to program a saccade to the next word $n+1$. Visual attention and the eyes remain on the foveal word until it is completely processed. Upon full identification of the word $n$, attention shifts to word $n+1$ and the eyes are expected to follow as soon as the eye movement programming is completed. If, however, in the mean time the familiarity check of word $n+1$ happens and if the programming of the initial eye movement has not yet reached its final ballistic stage, then the eye movement program towards word $n+1$ can be cancelled and replaced by a new program to word $n+2$. In this situation, skipping of word $n+1$ will take place. Because of the above sequence of events, it is the processing ease of word $n+1$ that influences the likelihood of it being skipped and this ease is determined by word frequency and contextual predictability. ${ }^{3}$ In addition to language variables, visual factors such as word length and launch site have a role in the E-Z Reader model as well, because they limit the amount of early visual processing (in $\mathrm{ms}$ ) that is completed during a fixation. The E-Z Reader model assumes an inverse relation between the extraction of letter information and the distance of the letter from the centre of the visual field. Hence, a longer word on the right of the foveal word will decrease the probability that the programmed eye movement to word $n+1$ is replaced by an eye movement to word $n+2$.

So, both the EOVP model and the E-Z Reader model incorporate visual as well as language-related factors to calculate the probability that a parafoveal word will be skipped. However, there are two main differences. First, EOVP puts the primacy on the visual variables of word length and launch site (see Figure 1), whereas in the mathematical elaboration E-Z Reader sees a primary role for word frequency and context predictability. The second difference between EOVP and E-Z Reader is that in the latter model word skipping nearly always occurs because the parafoveal word was processed. In the EOVP model, the difference between easy and difficult words is hypothesised to be due more to cancelled skips for difficult words than to extra skips for easy words. The latter agrees with the finding that word skipping is often followed by a short fixation duration and a regressive eye movement (Brysbaert \& Vitu, 1998; Vitu

\footnotetext{
${ }^{3}$ To test the viability of the E-Z Reader model, Reichle et al. (1998) compared the results of the model on a set of sentences with human eye movement data that had been gathered before. For each word of the sentences context predictability was assessed with the use of the sentence completion task. A similar approach was followed to test another recent computational model of eye guidance in reading, the so-called SWIFT model (Engbert, Longtin, \& Kliegl, 2002).
} 
\& McConkie, 2000), as if the oculomotor system by the time of the skip received a signal that the initial educated guess was wrong.

The present experiment was designed to further test what happens when the variables word length and contextual constraint are manipulated simultaneously. Given that the effect of contextual constraint on the probability of word skipping is stronger than the effect of word frequency, it seems worthwhile to verify whether word length in this situation still plays the basic role, as claimed by the EOVP model, or whether contextual constraints (which build up over several words and can be fed to the language system before the target word is encountered) will be playing the leading part, as claimed by the E-Z Reader model. In Brysbaert and Vitu's (1998) meta-analysis (Figure 1), the word length variable was largely a between-experiments variable (i.e., the data for the different word lengths came from different articles), whereas the contextual constraints variable was a repeated measure (i.e., was obtained within a single experiment with the same participants reading high and low predictable words in a random sequence). Needless to say, this opens the possibility that some of the word length effect was due to confounded variables.

A second, related question is whether cross-talk is possible between the EOVP-based information system and the language processor. Basically, what the EOVP system provides is information about the length of the upcoming word blob. There is, however, one situation in which this information could be very useful to the language system, namely when contextual constraints well in advance predict the length of the upcoming word. Suppose you get the following sentence (from Rayner et al., 2001): "Most cowboys know how to ride a ... if necessary." Virtually all (American) readers expect the five-letter word "horse" to appear after the sequence "to ride a". Fewer expect the five-letter word "llama" or the twelve-letter word "hippopotamus". However, the difference between both unexpected continuations is that the first (llama) agrees with the predicted word length, whereas the second (hippopotamus) clearly violates the expectation. Will the system be fooled by the fact that the lengthpreserving intruder strongly resembles the expected word blob, or will it make no difference whether the intruder is of a different length as the expected word?

To investigate our research questions, we constructed two sets of sentences. The first set consisted of sentences in which a two-letter word was strongly expected on the basis of the preceding sentence context, and we presented either this two-letter word, or an unexpected but still acceptable two-letter word, or an unexpected but acceptable four-letter word. We also constructed a second set of sentences in which a four-letter word was expected from the context and we presented this word, an intruder of the same length, or an intruder of two letters. The combination of these six conditions allowed us to investigate the effects of word length and predictability separately (by comparing the skipping rates for the different lengths and predictability ratios while the other variable was held constant). It also allowed us to see whether an unexpected two- or four-letter 
word is more likely to be fixated when in addition to being unpredictable from the context, it also violates the length expectations (we could achieve this by comparing the skipping rates for unexpected two-letter words when a two-letter word was expected vs. when a four-letter word was expected, and by comparing the skipping rates for unexpected four-letter words when a four-letter word was expected vs. when a two-letter word was expected).

To obtain a significant effect of contextual constraints on skipping behaviour, it is necessary to ensure that the contextual manipulation is powerful enough (Hyönä, 1993; Rayner \& Well, 1996). Therefore, we took great care to construct stimulus materials that very strongly raised the expectation of a particular word. In addition, we worked with short words that could easily be identified in the parafovea, and with a kind of stimuli that allowed predictions as low as the lexical level. ${ }^{4}$ This kind of optimal stimuli is provided by the separable verbs in Dutch. These verbs consist of two parts that can be written quite far apart from one another. For example, the verb opvallen (to attract attention), consists of two parts: a particle $(o p)$ and a nonseparable verb (vallen), which in itself has another meaning (i.e., to fall). Because the meaning of separable verbs can differ from that of the nonseparable verb part, it is generally assumed that the lexicon temporarily has to keep several different word forms activated (Kempen, 1995; Schreuder, 1990). Otherwise, it is difficult to understand why Dutch-speaking people have no difficulties understanding the sentence "Door zijn oranje haarbos viel ${ }^{5}$ de punker op." (literally: Because of his orange hair fell the punk up [in reality: Because of his orange hair the punk attracted a lot of attention]).

The particles of separable Dutch verbs were used in our experiment as the target words ${ }^{6}$ and the nonseparable verb always preceded the target by several words. This gave us two advantages. The first is of a practical nature; it is relatively easy to construct sentences in Dutch for which the particle is strongly expected from the context. The second reason is that the lexical node representing the separable verb is likely to be activated during the fixation prior to potential skipping, thus maximising the opportunity for linguistic influences to encourage skipping. Because there is some evidence that context effects are

\footnotetext{
${ }^{4}$ Hyönä (1993) did not find a significant difference in skipping rate due to contextual constraints. $\mathrm{He}$ attributed this to the possibility that the difference in sentence completion ratios in his stimulus materials (32\% low predictable versus $65 \%$ highly predictable) was not large enough. Recently, however, an alternative explanation has been put forward (Calvo \& Meseguer, 2002; Calvo, Meseguer, \& Carreiras, 2001). Calvo et al. suggest that a distinction should be made between contextual predictability based on associative priming among the various words in the sentence (e.g., the word wedding priming the word cake), and contextual predictability based on more elaborative inferences at the discourse level. The former could affect early processing stages such as skipping probability, whereas the latter only affects later processing stages. Calvo et al. suggest that the stimuli used by Hyönä may have belonged to the latter category.

${ }^{5}$ viel [fell] is the simple past singular tense of the verb vallen [to fall].

${ }^{6}$ Keep in mind that the term "target word" refers to the two- or four-letter particle parts of the separable verbs.
} 
stronger when the contextual constraints have been built up for several sentences (Ehrlich \& Rayner, 1981) we also chose to use text passages that filled five lines of text on the screen. The target appeared about halfway along the fourth line. An example sentence with a two-letter predictable word is shown in Table 1, one with a four-letter predictable word is shown in Table 2 .

\section{METHOD}

\section{Participants}

Fifty-seven first-year university students of Ghent University participated in the experiment which involved two sessions of one hour each. They all had normal uncorrected vision and were native speakers of Dutch.

\section{Apparatus}

Eye movements were recorded by a Senso-Motoric Instruments (SMI Eyelink) video-based pupil tracking system. Viewing was binocular but eye movements were recorded from the right eye only. A high-speed video camera was used for recording. It was positioned underneath the monitored eye and held in place by head-mounted gear. The system has a visual resolution of 20 seconds of arc.

TABLE 1

Example sentence for a two-letter predictable word

Preceding context:

Hanneke begon haar stage als verpleegster. Na een lange en zware opleiding was ze blij dat ze eindelijk eens kon ervaren hoe het er allemaal praktisch aan toe gaat. Een vroedvrouw begeleidde haar bij de eerste taak. Hanneke maakte het bed

Continuations:

2-letter word predictable $o p$ volgens de instructies van de vroedvrouw.

2-letter word neutral $\quad n a$ volgens de instructies van de vroedvrouw.

4-letter word neutral vast volgens de instructies van de vroedvrouw.

Following context:

Daarna werd de vroedvrouw weggeroepen en stond ze er alleen voor.

Translation:

Hanneke started her internship as a nurse. After a long and hard training she was happy to finally experience how things were done in the real world. A midwife helped her on her first task. Hanneke

Continuations:

2-letter word predictable made the bed according to the midwife's instructions.

2-letter word neutral imitated the bed according to the midwife's instructions.

4-letter word neutral fastened the bed according to the midwife's instructions.

Following context:

Then, the midwife was called away and she was on her own. 
TABLE 2

Example sentence for a four-letter predictable word

Preceding context:

Op een vrije namiddag besloot ik iets aan mijn kookkunst te doen. Om het eenvoudig te houden wilde ik beginnen met het bereiden van pudding. Een tijdje nadat ik de melk op het vuur had gezet, hoorde ik mijn moeder roepen: Haast je of de melk kookt

Continuations:

4-letter word predictable over en dan is de pudding niet lekker meer.

4-letter word neutral door en dan is de pudding niet lekker meer.

2-letter word neutral in en dan is de pudding niet lekker meer.

Following context:

Het was echter al te laat en ik kon opnieuw beginnen.

Translation:

On a free afternoon I decided to do something about my cookery skills. To keep it simple I started with preparing a pudding. A while after I put the milk on the heat, I heard my mother calling: Hurry or the milk will boil

Continuations:

4-letter word predictable over and the pudding won't taste good anymore.

4-letter word neutral through and the pudding won't taste good anymore.

2-letter word neutral down and the pudding won't taste good anymore.

Following context:

However, it was already too late and I had to start over again.

Fixation locations were sampled every $4 \mathrm{~ms}$ and these raw data were used to determine the different measures of oculomotor activity during reading. The display was $69 \mathrm{~cm}$ from the subject's eye and three characters equalled $1^{\circ}$ of visual angle. A chin rest was used to reduce head movements during the experiment.

\section{Materials}

Thirty-six target sentences with a preceding context were created. ${ }^{7}$ Half of the target sentences were built from a strongly expected two-letter word; half from a strongly expected four-letter word. For each sentence, two additional variants were made by replacing the expected target word by an acceptable but unexpected word of the same length and an acceptable but unexpected word of the complementary length. To validate our stimulus materials, a group of 40 firstyear students who did not participate in the eye-tracking experiment were presented with the sentence frames up to the target word and asked to produce the next word in the sentence. For the target sentences with an expected two-letter

\footnotetext{
${ }^{7}$ All materials are available from the first author upon request, denis.drieghe@Ugent.be
} 
target word, the sentence completion ratios were .82, .003, and .003 for the expected two-letter word, the unexpected two-letter word, and the unexpected four-letter word respectively. Virtually the same completion ratios were obtained for the sentences with an expected four-letter word: .82, .004, and .006 for the expected four-letter word, the unexpected four-letter word, and the unexpected two-letter word. In the selection of the target words, we matched the conditions as closely as possible on the frequency of the separable verbs. The mean frequency per million for the two two-letter and the one four-letter targets according to the CELEX database for Dutch (Baayen, Piepenbrock, \& Van Rijn, 1993) were respectively $28.4,14.8$, and 7.4. For the target sentences with two possible four-letter target words and one two-letter word the mean frequency per million were respectively $21.3,14.8$, and 20.2. Because we were not able to fully match the conditions on frequency this factor will be considered in the data analysis. The sentences could have alternative endings, depending on the target word used. This was done to insure that the sentences as a whole remained plausible. O'Regan $(1990,1992)$ hypothesised that readers adopt a global reading strategy (e.g., careful or risky reading) that influences the fixation times and saccade lengths. It is not inconceivable that an implausible sentence ending could lead to a more careful strategy on the following trials, thus influencing skipping behaviour. Precautions were also taken to insure that the alternative endings all had the same continuations in terms of word lengths and spacing for at least 10 characters following the target word. If not, this would affect the global visual configuration surrounding the target (cf. the global effect).

\section{Procedure}

Before the experiment started, participants were informed that the study was about reading comprehension of short texts, which would be displayed on a screen. Text administration was self-paced. The passages of the text were presented as a whole. Participants indicated when they had finished reading the text passage by pressing a button. They were told to read at their normal rate and that periodically they would be asked to answer a comprehension question about the passages. This was done on one quarter of the trials. The participants had no difficulty answering the questions; the questions were simple true-false statements, and the participants were correct $90 \%$ of the time. The initial calibration of the eye-tracking system generally required approximately $10 \mathrm{~min}$ and consisted of a standard 9-point grid. Following the initial calibration the participant was given 10 practice trials to become familiar with the procedure before reading the experimental sentences. The 36 experimental sentences were embedded in a pseudorandom order in 220 filler sentences. Each participant was presented one of the three possible conditions per sentence according to a Latin-square design. Participants completed two 1 hour sessions, each session containing 128 trials. 


\section{RESULTS}

Our primary dependent variable of interest was the probability of skipping the target word. We also calculated fixation times on the target words to check whether our patterns of data were compatible with prior findings. Because the word length of the target words was very short (i.e., two letters and four letters) there were virtually no double first-pass fixations on the target words. Only in $5.6 \%$ of the cases was a fixation on the target word in first-pass followed by a refixation. Therefore, only single fixation durations (i.e., the duration of the fixation on the target given that there was only one fixation on the target) will be reported, together with the total fixation times (including regressions on the target). The region used for computing target word fixations consisted of the letters of the target word together with the space in front of the target word and only first-pass skipping was considered. The target word was presented halfway through the fourth line. However, for two stimuli with a predictable two-letter word the targets were presented closer to the beginning of the fourth line. This caused a lot of participants to directly fixate on the target or past the target, when coming from the third line and making a return sweep to the fourth line $(92 \%$ of the cases for these two stimuli). Because we wanted to control our data for launch site, these two stimuli were excluded from the analyses; $7.7 \%$ more data were eliminated due to four possible reasons: (1) track loss, (2) the participant's first fixation in the fourth line was directly on the target or past the target, (3) the participant had not read all five lines when he/she pressed the button to indicate that they had reached the end of the text, and (4) the fixation was shorter than 100 ms (see Morrison, 1984, and Rayner, Sereno, Morris, Schmauder, \& Clifton, 1989, for justification). Because a Latin-square design was used with relatively few observations in the different cells, the group variable was included in all analyses reported below. If this is not done, the power of the design may be deflated because of random fluctuations between the participants or between the stimuli allocated to the different cells (Brysbaert \& Mitchell, 1996; Pollatsek \& Well, 1995). All analyses were run over participants ( $F 1$-analyses) and stimulus materials ( $F 2$-analyses).

\section{Skipping probability}

The skipping probabilities for the different conditions are shown in Table 3 . Separate ANOVAs were run for the two different sentence sets. For the sentences with the expected two-letter words, our manipulation of predictability was significant, $F 1(2,108)=23.54, M S E=0.04, p<.001 ; F 2(2,26)=17.34$, $M S E=0.01, p<.001$. This effect, however, was largely due to the difference between the unexpected four-letter words on the one hand and the two-letter words on the other hand. Contrasts showed that the difference between the predicted and the unpredicted two-letter words did not reach significance in a 
TABLE 3

Skipping probability and fixation time measures (in $\mathrm{ms}$ ) on the target word as function of contextual constraint and target word length

\begin{tabular}{lcccc}
\hline Constraint & $\begin{array}{c}\text { Word } \\
\text { length }\end{array}$ & $\begin{array}{c}\text { Skipping } \\
\text { probability }\end{array}$ & $\begin{array}{c}\text { Single fixation } \\
\text { duration }\end{array}$ & $\begin{array}{c}\text { Total fixation } \\
\text { duration }\end{array}$ \\
\hline Sentences with expected two-letter words & & & & \\
$\quad$ Predicted & 2 & .79 & 219 & 236 \\
$\quad$ Neutral & 2 & .74 & 232 & 385 \\
$\quad$ Neutral & 4 & .56 & 235 & 413 \\
Sentences with expected four-letter words & & & & \\
$\quad$ Predicted & 4 & .55 & 230 & 283 \\
$\quad$ Neutral & 4 & .46 & 239 & 329 \\
$\quad$ Neutral & 2 & .71 & 230 & 289 \\
\hline
\end{tabular}

two-tailed test ( 2 pr vs. 2 unpr: $t 1=1.53, p>.10 ; t 2<1$, n.s.; 2 pr vs. 4 unpr: $t 1$ $=5.78, p<.001 ; t 2=7.99, p<.001 ; 2$ unpr vs. 4 unpr: $t 1=5.16, p<.001 ; t 2=$ $3.68, p<.001$; all the reported $p$ values were Bonferroni adjusted).

For the sentence group with the expected four-letter words, the effect of target type was significant as well, $F 1(2,108)=26.76, M S E=0.03, p<.001$; $F 2(2,30)=12.61, M S E=0.02, p<.001$. The difference in skipping rate for the expected four-letter words and the unexpected four-letter words reached the significance level for the $F 1$ analysis but not for the analysis over stimuli ( $4 \mathrm{pr}$ vs. 4 unpr: $t 1=2.30, p<.05 ; t 2=1.22, p>.10 ; 4$ pr vs. 2 unpr: $t 1=-4.09, p<$ $.001 ; t 2=-3.38, p<.01 ; 4$ unpr vs. 2 unpr: $t 1=7.72, p<.001 ; t 2=-4.23, p<$ $.001)$.

The skipping rates for unexpected two-letter words were very similar when they replaced an expected two-letter word (74\%) and when they replaced an expected four-letter word (71\%). In a one-way between groups ANOVA run on the stimuli data they did not differ significantly from each other, $F 2(1,32)<1$, n.s. Although there seemed to be a bigger difference for the unexpected fourletter words when they substituted an expected four-letter word (46\% skipping) than when they substituted an expected two-letter word (56\% skipping), the ANOVA showed that these two values did not differ significantly from each other either, $F 2(1,32)=1.16, M S E=0.04, p>.10$.

To further examine the relative effects of word length and word predictability, we ran a multiple linear regression analysis on the skipping rates for all the $34 \times 3=102$ test sentences. Four predictors were entered: word length, sentence completion rate, log frequency per million, and average launch site. Frequency was entered in the analyses because in our stimulus selection it was not possible to completely match the frequency in all the conditions. Because word skipping depends on launch site, we entered this variable as a predictor as 
well. The results were quite straightforward: Word length emerged as the only significant variable, $t(97)=6.43, p<.001$, explaining $31 \%$ of the variance. Word predictability was not significant, $t(97)=1.41, p>.10$, nor was word frequency, $-1<t(97)<1$, n.s. Finally, average launch site per sentence failed to predict average word skipping rate too, $-1<t(97)<1$, n.s., although there was a clear difference in launch site between the sentences in which a word was skipped and the sentences in which the word was fixated, as shown in Table 4. Launch sites were more than two letter positions further away when the target word was fixated than when it was skipped, both for the conditions with the expected two-letter words, $F 1(1,129)=74.03, M S E=7.25, p<.001, F 2(1,47)=$ 27.39, $M S E=5.42, p<.001$, and for the conditions with the expected four-letter words, $F 1(1,152)=108.18, M S E=6.95, p<.001, F 2(1,53)=87.86, M S E=$ $2.71, p<.001$.

\section{Fixation times}

Table 3 also displays the single fixation durations and the total fixation durations for the different sentence types. For the sentences with expected two-letter words, the effect of target type was not significant for the single fixation durations, $F 1(2,38)=1.07, M S E=4125, p>.10, F 2(2,20)=2.51$, $M S E=1563, p>.10$. A different pattern was found for the total fixation durations: The main effect of target type was significant, $F 1(2,42)=9.19$, $M S E=21,857, p<.001 ; F 2(2,20)=21.32, M S E=6162, p<.001$, and the predictable two-letter words differed significantly from the neutral two-letter words and neutral four-letter words but the latter two were not significantly different from each other ( 2 pr vs. 2 unpr: $t 1=-3.41, p<.01 ; t 2=-2.80$, $p<.01 ; 2$ pr vs. 4 unpr: $t 1=-7.03, p<.001 ; t 2=-10.84, p<.001 ; 2$ unpr vs. 4 unpr: $t 1<1$, n.s.; $t 2<1$, n.s.).

For the single fixation durations of the expected four-letter words the effect of target type was not significant, $F 1(2,78)<1$, n.s.; $F 2(2,28)<1$, n.s. For total

TABLE 4

Mean launch site in function of target type and skipping

\begin{tabular}{lcc}
\hline & \multicolumn{2}{c}{ Launch site } \\
\cline { 2 - 3 } Word length constraint & Skipping & No skipping \\
\hline 2 predicted & 5.82 & 9.35 \\
2 neutral & 5.29 & 9.20 \\
4 neutral & 5.63 & 7.20 \\
4 predicted & 5.07 & 8.29 \\
4 neutral & 5.19 & 7.77 \\
2 neutral & 5.19 & 8.44 \\
\hline
\end{tabular}


fixation durations, the main effect of target type was significant over participants, $F 1(2,80)=4.16, M S E=10,345, p<.05$, and over stimuli, $F 2(2,28)=$ $4.85, M S E=4242, p<.05$. The neutral four-letter word target differed significantly from the predictable four-letter word but the other comparisons did not differ significantly from each other ( 4 pr vs. 4 unpr: $t 1=-2.27, p<.01 ; t 2=$ $-3.28, p<.05 ; 4$ pr vs. 2 unpr: $t 1<1$, n.s.; $t 2<1$, n.s.; 4 unpr vs. 2 unpr: $t 1=$ $2.04, p>.05 ; t 2=2.06, p>.05)$.

\section{Eye movements after the target word}

The difference in total fixation times between sentences with expected and unexpected words is a first indication that the former type of sentence indeed induced the processing difficulties we aimed at. To obtain more information about the extent to which the unexpected sentence continuations disturbed the ongoing processing, we looked at regression probabilities and spillover effects. Table 5 shows the percentage of immediate regressions to the target word both when this word had been skipped and when it had been fixated. First, it is clear that regressions were more likely in sentences with unexpected words $(18 \%)$ than in sentences with expected words (10\%). In addition, the data in Table 5 replicated Vitu and McConkie's (2000) finding that immediate regressions are more likely after a word has been skipped (19\%) than after it has been fixated (11\%). Finally, regressions to two-letter words $(12 \%)$ were less likely than regressions to fourletter words $(18 \%)$. The effects of these three variables can easily be estimated by using them as predictors in a multiple regression analysis with the probabilities of regressive eye movements listed in Table 5 as dependent variable.

To look at the total disruption caused by the unexpected continuations, we also calculated the Cumulative Region Reading Time (CRRT) for the two-word region after the target. The CRRT (Brysbaert \& Mitchell, 1996) is the sum of all fixations from the moment the eyes cross the front boundary of the region to the

TABLE 5

Probability of regression to the target in function of target type and skipping

\begin{tabular}{lcc}
\hline & \multicolumn{2}{c}{ Probability of regression } \\
\cline { 2 - 3 } Word length constraint & Skipping & No skipping \\
\hline 2 predicted & .125 & .023 \\
2 neutral & .228 & .105 \\
4 neutral & .275 & .219 \\
4 predicted & .153 & .080 \\
4 neutral & .208 & .163 \\
2 neutral & .166 & .062 \\
\hline
\end{tabular}


TABLE 6

Cumulative region reading time for the two-word region past the target in function of target type (in ms)

\begin{tabular}{lc}
\hline Word length constraint & CRRT \\
\hline 2 predicted & 473 \\
2 neutral & 689 \\
4 neutral & 630 \\
4 predicted & 440 \\
4 neutral & 601 \\
2 neutral & 625 \\
\hline
\end{tabular}

moment they cross the back boundary. ${ }^{8}$ It includes the first-pass gaze duration of the region, all the fixation durations of the regressive movement (if there is one), and the rereading of the critical region after the regression. CRRTs as a function of the different sentence types are shown in Table 6 . These data clearly illustrate the processing difficulties induced by the unexpected words.

\section{DISCUSSION}

The first goal of the current study was to test one of the core assumptions of the Extended Optimal Viewing Position (EOVP) model of eye guidance in reading (Brysbaert \& Vitu, 1998). This model states that the most important factor in word skipping is the length of the upcoming word, even when words are highly expected on the basis of the sentence context. Because the model has been formulated in mathematical terms, it is possible to predict the effects due to word length and context predictability quantitatively. More specifically, percentage skipping rate for predictable words is assumed to be equal to $100\left(\mathrm{e}^{-0.34}\right.$ word length $)+5$; and that of unpredictable words to $100\left(\mathrm{e}^{-0.34 \text { word length }}\right)-5$. Thus, for two-letter words, the expected skipping rates are $56 \%$ and $46 \%$ for predictable and unpredictable words respectively; for four-letter words, they are $31 \%$ and $21 \%$. These can be compared with the data obtained in the present experiment (see Table 3). Expected two-letter words resulted in a skipping rate of $79 \%$, unexpected two-letter words in a skipping rate of $72 \%$ (averaged across the two conditions with unexpected two-letter words). Expected four-letter words induced a skipping rate of 55\% for the predictable words and $51 \%$ for the unpredictable. Although the skipping rates in our experiment were considerably

\footnotetext{
${ }^{8}$ Measurements exist that are similar or the same as the CRRT, e.g., the Regression Path Reading Time. For a discussion on the benefits of such measurements see Liversedge, Paterson, and Pickering (1998).
} 
higher than expected on the basis of the EOVP model (possibly because the sentences were not presented in isolation but as part of a text passage), the model successfully predicted the $75 \%-52 \%=23 \%$ difference between two-letter words and four-letter words ( $25 \%$ difference predicted). In addition, the impact of the word length variable was more pronounced than that of word predictability, both in absolute terms and according to the regression analysis. An unpredictable two-letter word was more likely to be skipped (72\%) than a predictable fourletter word (55\%). To our knowledge, this is the first study that simultaneously manipulated word length and word predictability, and that confirmed Brysbaert and Vitu's predictions about word length in a repeated measures design.

In the predictable four-letter word conditions a difference of $9 \%$ in skipping rate due to contextual constraint was observed. This effect of predictability was reduced to a $5 \%$ difference in skipping rate in the two-letter word conditions. The fact that the effect was smaller in the two-letter word conditions may be due to ceiling effects: The 79\% skipping in the predictable twoletter word condition is among the largest thus far observed. As such, we believe that the $9 \%$ difference due to contextual constraint in the four-letter word conditions is the more accurate measure of the contextual constraint effect. This $9 \%$ difference is consistent with prior research (see Figure 1; and Brysbaert \& Vitu, 1998). ${ }^{9}$

Although the $9 \%$ difference is in line with previous studies and presents further evidence for the importance of linguistic variables in determining the probability of word skipping, it is clear that a difference of such a small size causes problems for a purely language-based model of eye movement control in reading. Remember that we had an $80 \%$ difference in completion scores between the expected and the unexpected words. This was the highest difference we could achieve and is in line with the differences that were used in other studies with length-matched stimulus materials. In addition, we worked with short words that are known to be skipped frequently (i.e., because they are often identified in parafoveal vision according to the E-Z Reader model). Still, we were not able to increase the difference in skipping rate between the expected and the unexpected words. Apparently, a 9\% difference is among the largest one can obtain with contextual constraints. This is double the $4 \%$ effect Brysbaert and Vitu (1998) revealed for word frequency, but some way short of the effects attributed to word frequency and contextual constraints in the E-Z Reader model. In our view, the importance of word length should be more directly considered in the model. Our bet is that a very large part of the frequency and contextual constraint effects that are currently presented as evidence in favour of the E-Z Reader model, will actually turn out to be word length effects in dis-

\footnotetext{
${ }^{9}$ The only effect of contextual constraint that clearly deviates in size from the present results is the $23 \%$ difference reported by Vonk (1984), but this finding has been questioned on methodological grounds (Brysbaert \& Vitu, 1998).
} 
guise, certainly as far as word skipping is concerned (see Calvo \& Meseguer, 2002 , for effects of word length on other first-pass reading time measures).

Another difference between the E-Z Reader model and the EOVP model is that in the former all word skips consist of a cancelled saccade to word $n+1$, which is replaced by a saccade to word $n+2$. This replacement process is assumed to require extra time, so that fixation durations prior to skipped words on average will be longer than fixation durations prior to fixated words (Reichle et al., 1998). Although Hogaboam (1993) and Pollatsek, Rayner, and Balota (1986) reported empirical evidence for an inflated fixation duration prior to skipping, the effect has subsequently been questioned by McConkie et al. (1994) and Radach and Heller (2000), who failed to find a reliable difference between the fixation duration distributions before skipped and unskipped words. However, the latter two studies were based on correlational data (i.e., large corpora of eye movements from free text reading) rather than on experimentally manipulated data. Therefore, we decided to check whether our better controlled data would confirm this prediction of the E-Z Reader model. For each sentence, we computed the average fixation duration before the critical saccade as a function of whether or not the target word was skipped. As can be seen in Table 7, no evidence whatsoever was found for an inflated fixation duration prior to skipping, rather the reverse. This is in line with the EOVP model which states that cancelled saccades are replaced with both longer and shorter alternatives, depending on the reason why the saccade was cancelled. The idea that target modification does not necessarily imply a delay of the saccade can also be found in the SWIFT model (Engbert et al., 2002). This recent computational model of eye movement control in reading focuses on a more spatially distributed view of lexical processing but also uses, like the E-Z Reader model, word frequency and predictability instead of word length as determinants of processing difficulty for predicting skipping rates.

TABLE 7

Fixation durations prior to the target in function of target type and skipping (in ms)

\begin{tabular}{lccc}
\hline & \multicolumn{2}{c}{ Prior fixation duration } & \\
\cline { 2 - 3 } Word length constraint & Skipping & No skipping & Difference \\
\hline 2 predicted & 206 & 203 & 3 \\
2 neutral & 202 & 193 & 9 \\
4 neutral & 198 & 224 & -26 \\
4 predicted & 204 & 217 & -13 \\
4 neutral & 205 & 216 & -11 \\
2 neutral & 207 & 218 & -11 \\
\hline
\end{tabular}


Finally, despite the main effects of contextual constraint and word length, there was no evidence for the interaction we looked for. We hypothesised in the framework of the EOVP model that a mismatch between the length of the expected parafoveal word and the length of the actually presented word might be picked up by the language processor in order to prevent a word skip over an unexpected word. If a word of two letters is strongly expected on the basis of the previous context, then information about the length of the parafoveal word cannot be used to make a decision between this word and a two-letter intruder, but it can be used to decide between this word and a four-letter intruder. Or formulated otherwise, an unexpected two-letter word should be more likely to be skipped in a sentence where a two-letter word is expected than in a sentence where a four-letter word is expected. Although it is always difficult to interpret a null-effect, certainly when the effect goes in the expected direction (as is the case for the two-letter words: $74 \%$ vs $71 \%$; see column 1 of Table 3 ), the findings of the four-letter words seem to go enough in the opposite direction ( $46 \%$ vs. $56 \%$ ) not to expect too much of a lack of power of the present experiment.

So, we failed to find evidence for the idea that the eye guidance system is sensitive to the match between global visual information extracted from the parafovea and word length anticipations based on the meaning of the text. Such cross-talk between low-level visual information and high-level language information was first suggested by Hochberg (1975) and also features in Clark and O'Regan's (1999) ideas about parafoveal word recognition. Inhoff, Radach, Eiter, and Juhasz (2003) recently called this view that knowledge of word length assumes linguistic function in the word recognition process the word length constraint hypothesis.

Our failure to find evidence for the parafoveal word length constraint hypothesis in eye guidance might be explained by assuming that word length can influence word recognition only if it is backed up by a minimum of incoming sensory (orthographic) information. This would be in line with Clark and O'Regan (1999) who ventured that word length in combination with information about the first and the last letter of the word determines parafoveal word recognition. Such a view would also agree with Marslen-Wilson's (1989) ideas of context influences on auditory word recognition. He claimed that such influences do not preactivate the next word but facilitate the processing of matching bottom-up information, so that the word is recognised faster. According to this view, the mismatching word " $n a$ " in Table 1 would not be mistaken for the expected word "op" on the basis of the word length because there is no minimum of matching sensory information entering the system. Skipping data which are compatible with this minimum of incoming information hypothesis were reported by Balota et al. (1985). They presented predictable words in the parafovea. The target words were either correctly spelled or had a misspelling in their last letters so that they effectively became nonwords. No 
difference in skipping rate was found between the predictable words and the nonwords that were based on these predictable words and that shared the same onset.

So, our results leave open the possibility that a combination of parafoveal word length information and text-based expectancies may be used in eye guidance, when there is enough matching bottom-up information (from the first letters or the outer letters). However, other recent evidence reported by Inhoff et al. (2003) tempers the enthusiasm about this possibility. Inhoff et al. manipulated the length information of parafoveal target words by either presenting the correct word or by replacing one middle letter of the word with a blank space so that it seemed as if there were two short words coming up in the parafovea (e.g., subject vs. sub ect). When the eyes crossed the invisible border in front of the target word, the display changed and the preview was replaced by the intended target word. In a first experiment, Inhoff et al. manipulated word length information and orthographic information about the parafoveal word. In the second experiment, the word length preview was manipulated for highfrequency and low-frequency words. In Experiment 1, strictly additive effects of word length preview and orthographic preview were found. No extra word processing advantage was observed when both the length and the orthographic properties of the preview matched the target word than could be expected on the basis of the individual main effects. Similar results were obtained in Experiment 2 , where the effect of word length preview did not differ for high- and lowfrequency words. These findings led Inhoff et al. to conclude that spatial and linguistic information are controlled by functionally autonomous processing systems.

On the basis of our findings and those of Inhoff et al. (2003), it seems to us that the most likely interpretation within the frame of the EOVP model is that word length information and linguistic information independently influence the skipping decision. Word length is used in the very beginning of the fixation to obtain a rough estimate of the chances of recognising the parafoveal word by the end of the fixation, and this estimate is used to decide whether or not to programme a saccade to this word. The initial decision can be overruled on the basis of the incoming linguistic information, but this latter decision does not take into account the word length information on which the original decision was based. These are two functionally independent subsystems.

Interestingly, whereas our context manipulation had a clear effect on the likelihood of skipping the target word, it failed to return a reliable effect on the duration of the first (and only) fixation on the target word, if this word was fixated. Looking at Table 3, we see an effect of some $11 \mathrm{~ms}$ between expected and unexpected words of the same length, together with a $6 \mathrm{~ms}$ difference between unexpected two-letter and four-letter words. This is in line with other evidence (e.g., McConkie \& Dyre, 2000; Schroyens et al., 1999) that fixation durations are not always fully determined by the ongoing processing of the 
fixated word. Apparently, the eye guidance system is sometimes programming one saccade ahead, meaning that processing difficulties have to be dealt with by means of regressions (see the total fixation durations in Table 3 and the regression probabilities in Table 5) or longer fixations on subsequent words (the so-called spillover effect). As Schroyens et al. argued, this may be due to a tension that exists between the need to fully process the foveal word and the urge to move the eyes fast enough to take optimal advantage of the parafoveal preview. On the other hand, it must not be forgotten that because of the high skipping rates associated with our short target words, the average fixation times were based on very small numbers of observations, so that we may not have been able to pick up the full size of the effect.

To summarise, the results of our study indicate a strong word length effect on skipping behaviour as well as an effect of contextual constraint. These effects, combined with the finding that expected word length did not influence skipping behaviour, add further evidence to the view that verbal and visual factors on word skipping are controlled by two functionally different subsystems.

PrEview proof published online September 2003

\section{REFERENCES}

Altarriba, J., Kroll, J. F., Sholl, A., \& Rayner, K. (1996). The influence of lexical and conceptual constraints on reading mixed-language sentences: Evidence from eye fixations and naming times. Memory and Cognition, 24(4), 477-492.

Baayen, R. H., Piepenbrock, R., \& van Rijn, H. (1993). The Celex Lexical Database [CD-ROM]. Linguistic Data Consortium, University of Pennsylvania, Philadelphia, PA.

Balota, D. A., Pollatsek, A., \& Rayner, K. (1985). The interaction of contextual constraints and parafoveal visual information in reading. Cognitive Psychology, 17(3), 364-390.

Blanchard, H. E., Pollatsek, A., \& Rayner, K. (1989). The acquisition of parafoveal word information in reading. Perception and Psychophysics, 46(1), 85-94.

Brysbaert, M., \& Mitchell, D. C. (1996). Modifier attachment in sentence parsing: Evidence from Dutch. Quarterly Journal of Experimental Psychology, 49A, 664-695.

Brysbaert, M., \& Vitu, F. (1998). Word skipping: Implications for theories of eye movement control in reading. In G. Underwood (Ed.), Eye guidance in reading and scene perception (pp. 125-147). Oxford, UK: Elsevier.

Brysbaert, M., Vitu, F., \& Schroyens, W. (1996). The right visual field advantage and the optimal viewing position effect: On the relation between foveal and parafoveal word recognition. Neuropsychology, 10(3), 385-395.

Calvo, M. G., \& Meseguer, E. (2002). Eye movements and processing stages in reading: Relative contribution of visual, lexical and contextual factors. Spanish Journal of Psychology, 5(1), 66-77.

Calvo, M. G., Meseguer, E., \& Carreiras, M. (2001). Inferences about predictable events: Eye movements during reading. Psychological Research, 65, 158-169.

Clark, J. J., \& O'Regan, K. J. (1999). Word ambiguity and the optimal viewing position in reading. Vision Research, 39(4), 843-857.

Drieghe, D., \& Brysbaert, M. (2001, September). Word skipping in reading: On the interplay of linguistic and visual factors. Paper presented at the conference of the European Society for Cognitive Psychology, Edinburgh, UK. 
Ehrlich, S. F., \& Rayner, K. (1981). Contextual effects on word perception and eye movements during reading. Journal of Verbal Learning and Verbal Behaviour, 20, 641-655.

Engbert, R., Longtin, A., \& Kliegl, R. (2002). A dynamical model of saccade generation in reading based on spatially distributed lexical processing. Vision Research, 42, 621-636.

Findlay, J. M., \& Walker, R. (1999). A model of saccade generation based on parallel processing and competitive inhibition. Behavioral \& Brain Sciences, 22(4), 661-721.

Gautier, V., O’Regan, J. K., \& Le Gargasson, J. F. (2000). “The-skipping”, revisited in French: Programming saccades to skip the article "les". Vision Research, 40, 2517-2531.

Henderson, J. M., \& Ferreira, F. (1990). Effects of foveal processing difficulty on the perceptual span in reading: Implications for theories of reading eye movements. Journal of Experimental Psychology: Learning, Memory, and Cognition, 16, 417-429.

Henderson, J. M., \& Ferreira, F. (1993). Eye movement control during reading: Fixation measures reflect foveal but not parafoveal processing difficulty. Canadian Journal of Experimental Psychology, 47(2), 201-221.

Hochberg, J. (1975). On the control of saccades in reading. Vision Research, 15(5), 620.

Hogaboam, T. W. (1983). Reading patterns in eye movement data. In K. Rayner (Ed.), Eye movements in reading (pp.309-332). New York: Academic Press.

Hyönä, J. (1993). Effects of thematic and lexical priming on readers' eye movements. Scandinavian Journal of Psychology, 34(4), 293-304.

Inhoff, A. W., Radach, R., Eiter, B. M., \& Juhasz, B. (2003). Distinct subsystems for the parafoveal processing of spatial and linguistic information during eye fixations in reading. Quarterly Journal of Experimental Psychology, 56A(5), 803-827.

Kempen, G. (1995). Processing separable complex verbs: Comments on Frazier, Flores d'Arcais, and Coolen (1993). Cognition, 54, 353-356.

Kerr, P. W. (1992). Eye movement control during reading: The selection of where to send the eyes. Unpublished doctoral dissertation, University of Illinois at Urbana-Champaign, Urbana, IL, USA.

Liversedge, S. P., Paterson, K. B., \& Pickering, M. J. (1998). Eye movements and measures of reading time. In G. Underwood (Ed.), Eye guidance in reading and scene perception (pp. 55-75). Oxford, UK: Elsevier.

Marslen-Wilson, W. (1989). Access and integration: Projecting sound onto meaning. In W. MarslenWilson (Ed.), Lexical representation and process (pp. 3-24). Cambridge, MA: MIT Press.

McConkie, G. W., \& Dyre, B. P. (2000). Eye fixations during reading: Models of frequency distributions. In A. Kennedy, R. Radach, D. Heller, \& J. Pynte (Eds.), Reading as a perceptual process (pp. 683-700). Oxford, UK: Elsevier.

McConkie, G. W., Kerr, P. W., \& Dyre, B. P. (1994). What are "normal" eye movements during reading: Toward a mathematical description. In J. Ygge \& G. Lennerstrand (Eds.), Eye movements in reading (pp. 315-327). Oxford, UK: Elsevier.

McConkie, G. W., Kerr, P. W., Reddix, M. D., \& Zola, D. (1988). Eye movement control during reading: I. The location of initial eye fixations on words. Vision Research, 28(10), $1107-1118$.

Morris, R. K., Rayner, K., \& Pollatsek, A. (1990). Eye movement guidance in reading: The role of parafoveal letter and space information. Journal of Experimental Psychology: Human Perception and Performance, 16(2), 268-281.

Morrison, R. E. (1984). Manipulation of stimulus onset delay in reading: Evidence for parallel programming of saccades. Journal of Experimental Psychology: Human Perception and Performance, 10(5), 667-682.

O'Regan, J. K. (1990). Eye movements and reading. In E. Kowler (Ed.), Eye movements and their role in visual and cognitive processes (pp. 395-453). Amsterdam: Elsevier.

O'Regan, J. K. (1992). Optimal viewing position in words and the strategy-tactics theory of eye movements in reading. In K. Rayner (Ed.), Eye movements and visual cognition: Scene perception and reading (pp. 333-354). New York: Springer-Verlag. 
O’Regan, J. K., \& Jacobs, A. M. (1992). The optimal viewing position effect in word recognition: A challenge to current theory. Journal of Experimental Psychology: Human Perception and Performance, 18, 185-197.

O’Regan, J. K., Lévy-Schoen, A., Pynte, J., \& Brugaillère, B. (1984). Convenient fixation location within isolated words of different length and structure. Journal of Experimental Psychology: Human Perception and Performance, 10(2), 250-257.

Pollatsek, A., Rayner, K., \& Balota, D. A. (1986). Inferences about eye movement control from the perceptual span in reading. Perception and Psychophysics, 40(2), 123-130.

Pollatsek, A., \& Well, A. D. (1995). On the use of counterbalanced designs in cognitive research: A suggestion for a better and more powerful analysis. Journal of Experimental Psychology: Learning, Memory and Cognition, 21(3), 785-794.

Radach, R., \& Heller, D. (2000). Relations between spatial and temporal aspects of eye movement control. In A. Kennedy, R. Radach, D. Heller, \& J. Pynte (Eds.), Reading as a perceptual process (pp. 165-191). Oxford, UK: Elsevier.

Radach, R., \& Kempe, V. (1993). An individual analysis of initial fixation positions in reading. In G. d'Ydewalle \& J. Van Rensbergen (Eds.), Perception and cognition: Advances in eye movement research (pp. 213-226). Amsterdam: North-Holland.

Rayner, K. (1975). The perceptual span and peripheral cues in reading. Cognitive Psychology, 7(1), $65-81$.

Rayner, K. (1979). Eye guidance in reading: Fixation locations within words. Perception, 8(1), $21-30$.

Rayner, K., Binder, K. S., Ashby, J., \& Pollatsek, A. (2001). Eye movement control in reading: Word predictability has little influence on initial landing positions in words. Vision Research, 41(7), 943-954.

Rayner, K., \& Fischer, M. H. (1996). Mindless reading revisited: Eye movements during reading and scanning are different. Perception and Psychophysics, 58(5), 734-747.

Rayner, K., \& McConkie, G. W. (1976). What guides a reader's eye movements? Vision Research, 16(8), 829-837.

Rayner, K., Reichle, E. D., \& Pollatsek, A. (1998). Eye movement control in reading: An overview and model. In G. Underwood (Ed.), Eye guidance in reading and scene perception (pp. 243-268). Oxford, UK: Elsevier.

Rayner, K., Sereno, S. C., Morris, R. K., Schmauder, A. R., \& Clifton, C. (1989). Eye movements and on-line language comprehension processes. Language and Cognitive Processes, 4, 1-50.

Rayner, K., Sereno, S. C., \& Raney, G. E. (1996). Eye movement control in reading: A comparison of two types of models. Journal of Experimental Psychology: Human Perception and Performance, 22(5), 1188-1200.

Rayner, K., \& Well, A. D. (1996). Effects of contextual constraint on eye movements during reading: A further examination. Psychonomic Bulletin and Review, 3(4), 504-509.

Rayner, K., Well, A. D., Pollatsek, A., \& Bertera, J. H. (1982). The availability of useful information to the right of fixation in reading. Perception and Psychophysics, 31(6), 537-550.

Reichle, E. D., Pollatsek, A., Fisher, D. L., \& Rayner, K. (1998). Toward a model of eye movement control in reading. Psychological Review, 105(1), 125-157.

Reichle, E. D., Rayner, K., \& Pollatsek, A. (1999). Eye movement control in reading: Accounting for initial fixation locations and refixations within the E-Z Reader model. Vision Research, 39(26), 4403-4411.

Reichle, E. D., Rayner, K., \& Pollatsek, A. (in press). The E-Z Reader model of eye movement control in reading: Comparisons to other models. Behavioral and Brain Sciences.

Schreuder, R. (1990). Lexical processing of verbs with separable particles. In G. E. Booij \& J. Van Marle (Eds.), Yearbook of morphology 1990 (pp. 65-79). Dordrecht, The Netherlands: Foris.

Schroyens, W., Vitu, F., Brysbaert, M., \& d'Ydewalle, G. (1999). Eye movements during reading: Foveal load and parafoveal processing. Quarterly Journal of Experimental Psychology, 52A(4), 1021-1046. 
Schustack, M. W., Ehrlich, S. F., \& Rayner, K. (1987). Local and global sources of contextual constraint in reading. Journal of Memory and Language, 26, 322-340.

Starr, M. S., \& Rayner, K. (2001). Eye movements during reading: Some current controversies. Trends in Cognitive Sciences, 5(4), 156-163.

Vitu, F. (1991). The existence of a center of gravity effect during reading. Vision Research, 31, 1289-1313.

Vitu, F., \& McConkie, G. W. (2000). Regressive saccades and word perception in adult reading. In A. Kennedy, R. Radach, D. Heller, \& J. Pynte (Eds.), Reading as a perceptual process (pp. 301326). Oxford, UK: Elsevier.

Vitu, F., O’Regan, J. K., Inhoff, A. W., \& Topolski, R. (1995). Mindless reading: Eye-movement characteristics are similar in scanning letter strings and reading texts. Perception and Psychophysics, 57(3), 352-364.

Vonk, W. (1984). Eye movements during comprehension of pronouns. In A. G. Gale \& F. Johnson (Eds.), Theoretical and applied aspects of eye movement research. Amsterdam: North-Holland.

Yang, S.-N., \& McConkie, G. W. (2001). Eye movements during reading: A theory of saccade initiation times. Vision Research, 41, 3567-3585. 